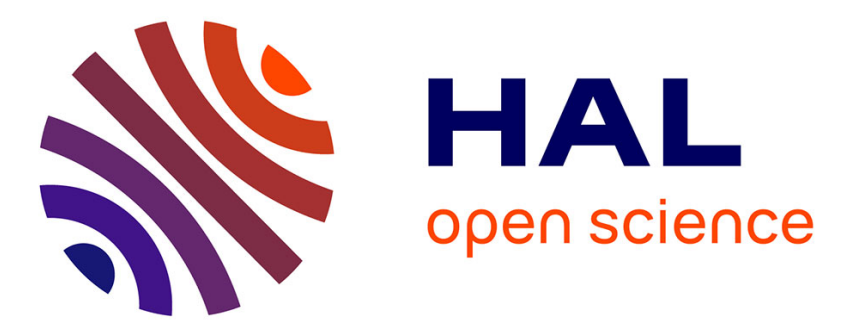

\title{
Linear and nonlinear viscoelastic properties of segmented silicone-urea copolymers: Influence of the hard segment structure
}

Guillaume Falco, Leo Simonin, Sandrine Pensec, Florent Dalmas, Jean-Marc Chenal, Laurent Bouteiller, Laurent Chazeau

\section{To cite this version:}

Guillaume Falco, Leo Simonin, Sandrine Pensec, Florent Dalmas, Jean-Marc Chenal, et al.. Linear and nonlinear viscoelastic properties of segmented silicone-urea copolymers: Influence of the hard segment structure. Polymer, 2020, 186, pp.122041. 10.1016/j.polymer.2019.122041 . hal-02917165

\section{HAL Id: hal-02917165 \\ https://hal.science/hal-02917165}

Submitted on 21 Sep 2020

HAL is a multi-disciplinary open access archive for the deposit and dissemination of scientific research documents, whether they are published or not. The documents may come from teaching and research institutions in France or abroad, or from public or private research centers.
L'archive ouverte pluridisciplinaire HAL, est destinée au dépôt et à la diffusion de documents scientifiques de niveau recherche, publiés ou non, émanant des établissements d'enseignement et de recherche français ou étrangers, des laboratoires publics ou privés. 


\title{
Linear and nonlinear viscoelastic properties of segmented silicone-urea copolymers: influence of the hard segment structure
}

\author{
Guillaume Falco ${ }^{\mathrm{a}}$, Léo Simonin ${ }^{\mathrm{b}}$, Sandrine Pensec ${ }^{\mathrm{b}}$, Florent Dalmas ${ }^{\mathrm{a}}$, Jean-Marc Chenal ${ }^{\mathrm{a}}$, \\ Laurent Bouteiller ${ }^{\mathrm{b}^{*}}$, Laurent Chazeau ${ }^{\mathrm{a}^{*}}$ \\ ${ }^{a}$ Univ Lyon, INSA-Lyon, CNRS, UCBL, MATEIS, UMR 5510, F-69621, Villeurbanne, \\ France
}

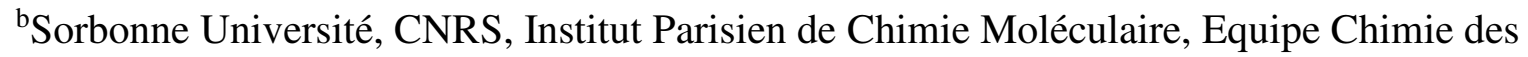

Polymères, 4 Place Jussieu, F-75005 Paris, France

*corresponding author: laurent.chazeau@insa-lyon.fr, laurent.bouteiller@upmc.fr

\begin{abstract}
The linear and non-linear viscoelastic behaviors of 5 segmented silicone copolymers - with low fraction of 1,6-hexamethylene diisocyanate (HDI), 4,4'-methylenebis(cyclohexyl isocyanate) (HMDI), 1,3bis(1-isocyanato-1-methylethyl)benzene (TMXDI), 2,4-tolylene diisocyanate (TDI) or isophorone diisocyanate (IPDI) as hard segments (HS) - are compared, in relation with their microstructure. When the HS are non-symmetrical, the materials nanostructuration is weak and has a limited impact on the mechanical response: two mechanical relaxations occur after the $\alpha$ relaxation of the polydimethylsiloxane (PDMS), the first related to the "unfreezing" of the HS-HS bonds, and the second one to the sticky reptation of the polymer chains. Conversely, when the HS are symmetrical, their selforganization is favored and the long range ordering of the HS is possible. The materials are then semicrystalline like, with a low crystallinity (due to the low weight percentage of HS) and their flow; possible above their melting temperature $\left(T_{m}\right)$, depends also on the HS dynamics, which is the most rapid for HDI.
\end{abstract}

\section{Keywords}

segmented copolymers; mechanical relaxations; nanostructure

\section{Introduction}

Silicone materials have generated a strong interest since their first commercialization because of their excellent mechanical and insulating properties at elevated temperatures[1]'[2]. The most widely used silicone is polydimethylsiloxane (PDMS) which, in most of its applications, is chemically crosslinked to form an elastomer. As this process creates non-recyclable materials, development of substitutes would be desirable to reduce their environmental impact. One of the possible alternatives is to use silicone elastomers in which the 3D network is created by reversible physical crosslinks. This can be achieved through the synthesis of segmented copolymers based on an apolar PDMS soft segment (SS) alternated with a polar self-associating hard segment (HS). Yilgor et al.[3],[4] were the first to synthesize this kind 
of copolymers with a regular alternation of PDMS and bis-urea segments (i.e. without chain extender). This combination leads to a microphase separation[5], even with low HS content, because of their solubility parameters $\left(\delta_{\text {PDMS }}=15.6\left(\mathrm{~J}_{\mathrm{cm}} \mathrm{cm}^{-3}\right)^{1 / 2} ; \delta_{\text {urea }}=45.6\left(\mathrm{~J}_{\mathrm{cm}}{ }^{-3}\right)^{1 / 2}\right)[6],[7]$. Other associating groups can be used in combination with PDMS segments, such as urethanes[8],[9]. The utilization of urea is

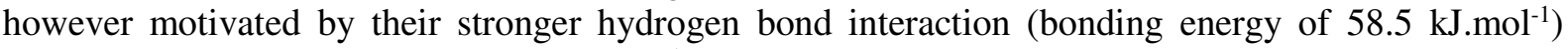
compared to urethane groups $\left(46.5 \mathrm{~kJ}^{\mathrm{mol}}{ }^{-1}\right)[9] \cdot[10]$. The former promotes the formation of a supramolecular structure [11], in which the presence of long filaments is often reported, explaining the copolymer interesting mechanical properties[12],[13],[14],[15], with modulus in the range or above those reported for chemically crosslinked elastomers. The dynamics of the hydrogen bonds can also potentially provide self-healing properties[16],[17],[18] which may be a key feature to increase the material lifetime.

These properties can be modulated according to HS content, the PDMS length or the HS length, in this latter case via the use of so called chain extenders[19]. The most common precursor used to form HS segment in silicone-urea copolymers is 4,4'-methylenebis(cyclohexylisocyanate) (HMDI). Several studies relate the microstructural and thermomechanical analysis of PDMS-HMDI copolymers with a high HS content $[6,19,20]$. Fewer studies on silicone-urea copolymers with low HS percentage $(<10 \% \mathrm{w})$ containing[12],[19]'[21] HMDI, 2,4-tolylene diisocyanate (TDI) or other isocyanates can also be found in literature. In these materials, Dynamic Mechanical Analysis (DMA) shows the existence of a first mechanical relaxation very similar and related to the one of the silicone segments, with a weak influence of the HS segment on its temperature. The crystallization and melting of the PDMS segments obviously depends on their length and may or may not be visible on the DMA curves. At larger temperature, a rubbery plateau is usually observed, whose height and temperature domain strongly depend on the content and the nature of the hard segments, followed at higher temperature, by one or two modulus drops. Tensile tests are also often reported and usually show at ambient temperature and moderate strain rate a pseudo-plastic behavior with a more or less pronounced hardening. A phenomenological relation of these properties with the microstructure is usually proposed. Thus, a direct link with the existence of a supramolecular structure, revealed by Atomic Force Imaging or X-rays scattering experiments, sometimes performed as a function of the temperature, has been suggested. Nevertheless, in these works, temperature appears as the varying parameter and the dynamic aspects of the mechanical response are not discussed, in spite of the importance of the dynamics of the HS association. This lack is particularly obvious in materials where the low content of HS may prevent the existence of a dense supramolecular structure with an extremely slow dynamic. Note that the same comment could be made regarding the literature on segmented polyurethane without use of chain extenders[22,23]. The understanding of the dynamic response of these materials is however mandatory to, for instance, properly evaluate their ability to flow or not at long time, as a function of temperature, and therefore to understand their possible self-healing properties. For the same purpose, it is also mandatory to better apprehend the impact of the chemical structure of the hard segment on the copolymer mechanical response.

To progress in this field, we synthesized 5 different silicone-urea copolymers with $M_{n} \sim 50000 \mathrm{~g}^{\mathrm{mol}}{ }^{-1}$ from a short PDMS length $\left(M_{n}\right.$ PDMS $\left.\sim 3250 \mathrm{~g} \cdot \mathrm{mol}^{-1}\right)$ and with $\sim 8 \mathrm{wt} \%$ of symmetrical or nonsymmetrical HS. Their microstructural investigation was done at room temperature by Atomic Force Microscopy (AFM) and Small-/Ultra-Small- X-ray scattering (SAXS/USAXS) and as a function of temperature by Differential Scanning Calorimetry (DSC), infrared spectroscopy (FTIR) and Wide-/ Small- X-ray scattering (WAXS/SAXS). The influence of this microstructure on the viscoelastic properties of the copolymers was evaluated by Dynamic Mechanical Analysis (DMA) over a very large frequency-temperature domain, in which different mechanical relaxations were observed. From master curves building (when possible), relaxation times and activation energies of the different processes were deduced and related to the chemical structure of the different HS. This complete analysis finally enables to understand the tensile behavior of this class of materials.

\section{Experimental part}




\subsection{Materials}

$\alpha, \omega$-bis( $\gamma$-aminopropyl)poly(dimethylsiloxane) $\left(M_{n}=3250\right.$ g.mol $\left.{ }^{-1}\right)$ was provided by Wacker. Isophorone diisocyanate (IPDI, 98\%), 4,4'-methylenebis(cyclohexyl isocyanate) (HMDI, 90\%, this is a mix of three different isomers), 1,6-hexamethylene diisocyanate (HDI, 99\%), 1,3-bis(1-isocyanato-1methylethyl)benzene (TMXDI, 97\%) and 2,4-tolylene diisocyanate (TDI, 95\%) were purchased from Sigma-Aldrich. Tetrahydrofuran isocratic grade not stabilized (THF) was received from Carlo Erba and dried before use.

\subsection{Synthesis}

The segmented silicone-urea copolymers were synthesized in solution at room temperature under $\mathrm{N}_{2}$ atmosphere from $\alpha, \omega$-bis( $\gamma$-aminopropyl)poly(dimethylsiloxane) and different diisocyanates (Figure 1). The diisocyanate (1eq.) was dissolved in dry THF $(1 / 10 \mathrm{w} / \mathrm{v})$. The diaminopropyl-terminated PDMS ( 1 eq.) was dissolved in dry THF ( $1 / 3 \mathrm{w} / \mathrm{v}$ ) and $1 / 3$ of this mixture was added to the diisocyanate solution and continuously stirred for 3 hours. Then, the $2 / 3$ remaining diaminopropyl-terminated PDMS solution was injected into the reactor with an automatic syringe pump $\left(2.5 \mathrm{~mL} \cdot \mathrm{h}^{-1}\right)$. At the end of the injection, the completion of the reaction was checked by FT-IR spectroscopy via the disappearance of the isocyanate peak at $2273 \mathrm{~cm}^{-1}$. Finally, the product was precipitated in methanol, the supernatant was removed and the sticky paste was dried under vacuum $\left(10^{-3} \mathrm{mbar}\right)$ at $70^{\circ} \mathrm{C}$ for two days. The final products were obtained with a yield from 77 to $88 \%$, except for the synthesis with HDI where the yield was $34 \%$. In this paper, the different samples are named PDMS-XX, where XX is the name of the diisocyanate used for the synthesis. Characterization were performed by ${ }^{1} \mathrm{H}$ NMR and size exclusion chromatography (see Figure S1 and Figure S2). As reported in Table 1 all the synthesized segmented copolymers display very similar molecular weights $\left(\sim 50000\right.$ g.mol $\left.{ }^{-1}\right)$, content of HS (from 8.3 to 10.8 $\%$ weight per polymer chain) and dispersity (Đ).

Bisurea-HS models were synthesized by reaction of 2-ethylhexylamine with the corresponding diisocyanate in dry dichloromethane and isolated by filtration (see the SI for synthesis method).

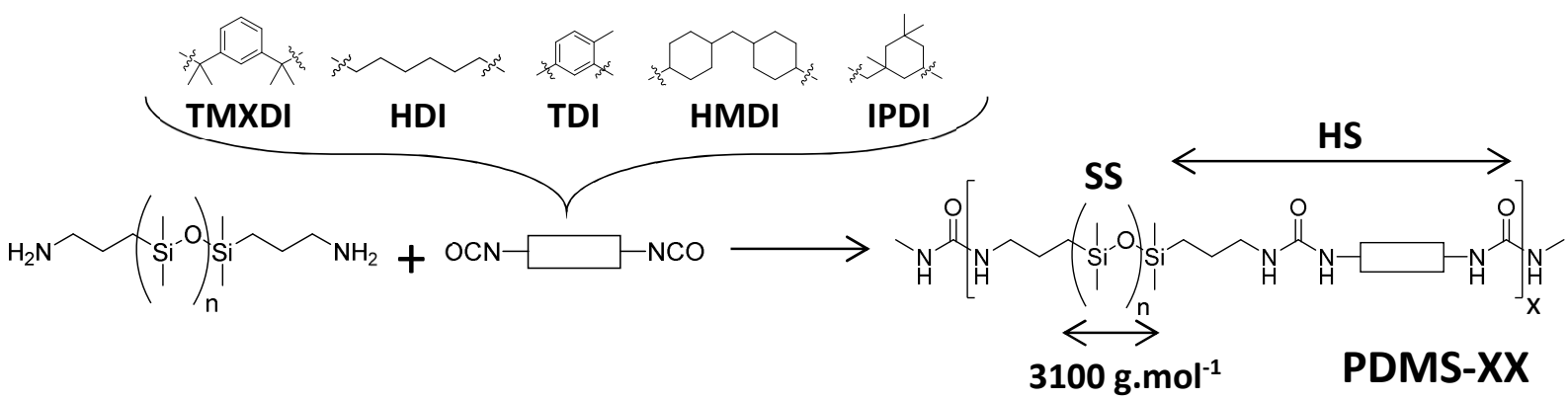

Figure 1: Structures of the different diisocyanates used as precursor of the associative HS and schematic structure of the copolymers PDMS-XX.

Table 1: Molecular weight $\left(M_{n}\right)$, HS content, average number of HS per polymer chain (m) and dispersity $(Ð)$ of the segmented silicone-urea copolymers

\begin{tabular}{ccccc}
\hline $\begin{array}{c}\text { Segmented silicone- } \\
\text { urea copolymers }\end{array}$ & $\begin{array}{c}M_{n} \\
\left(\mathrm{~g} \cdot \mathrm{mol}^{-1}\right)\end{array}$ & $\begin{array}{c}\text { HS content } \\
(\% \mathrm{wt})\end{array}$ & $\begin{array}{c}\text { Average number of HS per } \\
\text { polymer chain }(\mathrm{x})\end{array}$ & $Ð$ \\
\hline PDMS-TMXDI & 43300 & 10.3 & 12 & 1.9 \\
PDMS-HDI & 49600 & 8.3 & 13 & 1.8 \\
PDMS-TDI & 55600 & 8.5 & 15 & 1.6 \\
PDMS-HMDI & 48600 & 10.8 & 13 & 1.8 \\
PDMS-IPDI & 56800 & 9.7 & 15 & 1.8 \\
\hline
\end{tabular}




\subsection{Films processing}

Films of the copolymers were prepared by solvent casting. The solution in THF was poured into a closed polypropylene mold with a cover pierced with only a few holes in order to slow down the solvent evaporation. After 1 day, the mold was open and let 1 day at room temperature and ambient pressure, and 1 more day under vacuum $\left(10^{-3}\right.$ millibar $)$ at $60^{\circ} \mathrm{C}$. Finally, the film was removed from the mold and stored at room temperature. The film thickness was $\sim 0.7 \mathrm{~mm}$.

\subsection{Characterization}

Atomic force microscopy (AFM) was performed with a Dimension 3100 AFM device connected to a Nanoscope V scanning probe controller (VEECO Instruments, Plainview, NY). All images were obtained at room temperature in tapping mode using a pointprobe-plus ${ }^{\circledR}$ silicon (PPP-NCH-50) from Nanosensors with a high resonance frequency (ca. $300 \mathrm{kHz}$ ). A lateral resolution of 3-5 nm can be achieved by this configuration with a vertical resolution of $0.5 \mathrm{~nm}$. Surfaces of bulk samples were prepared by cryo-ultramicrotomy on a Leica UC7 microtome at $-150^{\circ} \mathrm{C}$ using a diamond knife from Diatome. All AFM images thus show the bulk microstructure of each sample. Very flat surfaces can be obtained with this technic, for this reason only phase images (highlighting a hard/soft contrast) are shown in the present paper.

Static small angle X-ray scattering (SAXS) and ultra-small angle X-ray scattering (USAXS) experiments were performed at room temperature on the ID2 beamline of the European Synchrotron Radiation Facility (ESRF), Grenoble (France). For SAXS measurements, the sample-detector distance was 1 meter and the exposure time was set at 0.5 second while for the USAXS investigations, the distance between sample and detector was 10 meters and the exposure time was set at 0.05 second. The SAXS/USAXS two-dimensional (2D) patterns of samples did not show any preferential orientation for the five copolymers. For this reason, the data presented are obtained from the azimuthal average of the scattering pattern from which all the necessary data corrections have been applied (background scattering subtraction and sample thickness correction). Static SAXS and wide-angle X-ray scattering (WAXS) were also performed as a function of the temperature on the D2AM beamline of the European Synchrotron Radiation Facility (ESRF), Grenoble (France). Each sample was heated at $10^{\circ} \mathrm{C} \cdot \mathrm{min}^{-1}$ up to $130^{\circ} \mathrm{C}\left(150^{\circ} \mathrm{C}\right.$ for PDMS-TDI $)$ and then at $3^{\circ} \mathrm{C} \cdot \mathrm{min}^{-1}$ up to $200^{\circ} \mathrm{C}$. Data were recorded during the two temperature ramps with a time delay of 10 seconds between each acquisition.

Differential scanning calorimetry (DSC) measurements were carried out on a Perkin Elmer DSC 8000 apparatus under $20 \mathrm{~mL} \cdot \mathrm{min}^{-1}$ nitrogen flow. Temperature and enthalpy calibrations were performed by using indium and zinc standards. Samples of about $10 \mathrm{mg}$ were placed into sealed $40-\mu \mathrm{L}$ alumina crucible and cooled down to $-50^{\circ} \mathrm{C}$ for $5 \mathrm{~min}$. Then, the heating and cooling measurements were conducted in a temperature range from $-50^{\circ} \mathrm{C}$ to $175^{\circ} \mathrm{C}$ at $2^{\circ} \mathrm{C} \cdot \mathrm{min}^{-1}$.

DMA experiments were performed in tensile mode with a TA Instruments DMA Q800 under $\mathrm{N}_{2}$ atmosphere with a $2^{\circ} \mathrm{C} \cdot \mathrm{min}^{-1}$ heating rate and $0.1 \%$ strain amplitude. The sample dimensions were 6.00 (length), $3.00 \mathrm{~mm}$ (width) and $0.70 \mathrm{~mm}$ (thickness) $( \pm 0.01 \mathrm{~mm})$. Rheological measurements were performed with an Anton Paar MCR 702 TwinDrive at $2^{\circ}$ C.min ${ }^{-1}$ under $\mathrm{N}_{2}$ atmosphere. A $25 \mathrm{~mm}$ parallel plate with $0.5 \mathrm{~mm}$ gap, a constant normal force of $0.1 \mathrm{~N}$ and $1 \%$ oscillatory shear deformation were applied. Each sample was placed on the lower plate at $160^{\circ} \mathrm{C}$ before reducing the gap by bringing down the upper plate. The G' and G' 'moduli collected from these rheological measurements were multiplied by a 3 factor (assuming a Poisson coefficient of 0.5 ) in order to obtain the E' and E'" tensile moduli. A good superimposition was obtained between the data obtained from both techniques, without any additional correction. The isothermal curves were also collected using the Anton Paar apparatus: The sample were first annealed at $160^{\circ} \mathrm{C}$ during few seconds, then one frequency sweep was applied at this temperature, with frequency ranging from 100 to $0.01 \mathrm{~Hz}$, with a $1 \%$ oscillatory shear deformation 
of $1 \%$. Frequency sweep (from 100 to $0.1 \mathrm{~Hz}, 1 \%$ shear amplitude) were then carried out from $160^{\circ} \mathrm{C}$ down to $30^{\circ} \mathrm{C}$, every $10{ }^{\circ} \mathrm{C}$.

Tensile measurements were performed on an INSTRON model 5565 with a loading cell of $100 \mathrm{~N}$ using the ISO4661-1 standard. Dog-bone-shaped samples of $20.00 \mathrm{~mm}$ (length), $4.00 \mathrm{~mm}$ (width) and 0.70 $\mathrm{mm}$ (thickness) $( \pm 0.01 \mathrm{~mm})$ were deformed at room temperature $\left(\sim 22^{\circ} \mathrm{C}\right)$ until failure with a nominal strain rate of $0.5 \times 10^{-2} \mathrm{~s}^{-1}$. The results are reported as nominal stress-nominal strain curves.

Self-healing tests were performed on rectangular samples of $3.00 \mathrm{~mm}$ width and $0.70 \mathrm{~mm}$ thickness at $50^{\circ} \mathrm{C}$. A controlled cut through half of the section was firstly done. Then, the two cut parts were put into contact by a slight pressure and placed on a lamella glass. The evolution of the slit was followed by optical microscopy on a ZEISS axiophot. A dark-field mode was used to increase the visibility of the slit by generating a dark background.

\section{Results}

\subsection{Microstructures}

AFM images were recorded from the material film cross-section (cf. Figure 2 and Figure 3), which should be more representative than the surface where solvent evaporation can lead to skin effects and to a different microstructure[24]. In spite of the rather low content of hard segment, the large difference in solubility parameters[6]'[7] between the hard (polar) and the soft (apolar) segments should generate a microphase separation, whose morphology depends on the nature of the associative blocks. Indeed, AFM images of PDMS-TMXDI (Figure 2a) shows kind of nodules of about 40 - $50 \mathrm{~nm}$ diameter that seem to be connected (see the Figure $\mathbf{S 3}$ in the SI for the intensity lines profiles). The structure of PDMS-HDI (Figure 2b) shows filaments-like objects with a distance of $\sim 20-30 \mathrm{~nm}$ in between them, slightly oriented in the film direction. Both materials have symmetrical hard segment conversely to PDMS-TDI and PDMS-IPDI, and to PDMS-HMDI (whose HS is a mixture of symmetrical and nonsymmetrical stereo-isomers[25]). In PDMS-TDI only, clustering of HS can also be evidenced, that forms filaments-like objects less defined than in PDMS-HDI, spaced of $\sim 15-20 \mathrm{~nm}$, without preferential orientation (Figure 3a). PDMS-HMDI (Figure 3b) and PDMS-IPDI (Figure 3c) images do not show clear nanostructuration at the scale of the AFM images.
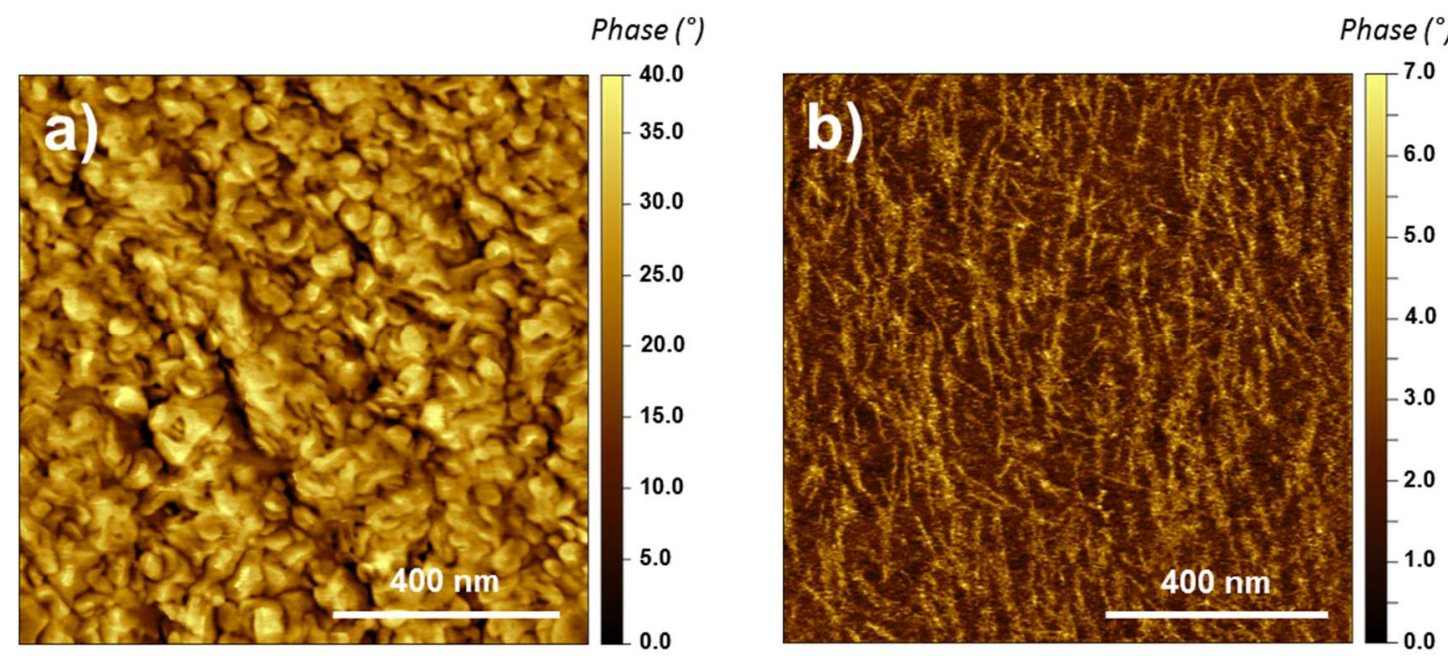

Figure 2: Tapping-mode AFM phase images at room temperature of a) PDMS-TMXDI and b) PDMSHDI. 

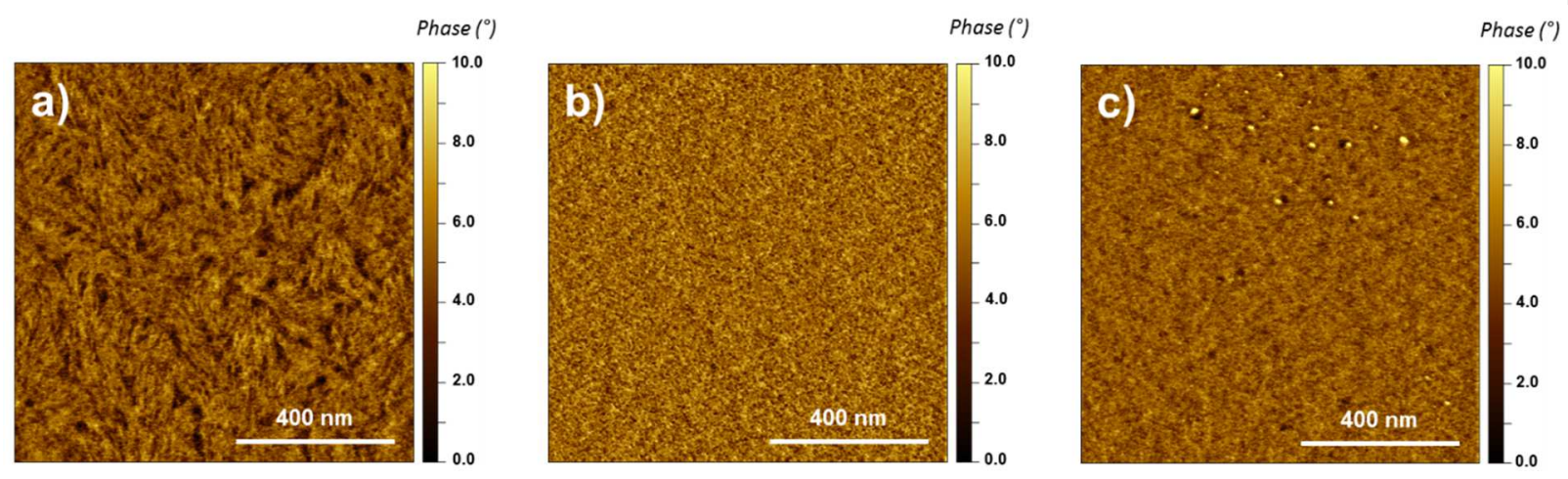

Figure 3: Tapping-mode AFM phase images at room temperature of a) PDMS-TDI, b) PDMS-HMDI and c) PDMS-IPDI.

SAXS and USAXS were performed on films placed perpendicularly to the beam. For all samples, isotropic scattering indicates no preferred orientation of the microstructure at the scale of the beam (100 x $200 \mu \mathrm{m}^{2}$ ), as shown for instance on Figure 4 (left). Corrected intensities, I $(q)$ are shown in Figure 4 (right) and Figure 5. For $q<0.1 \mathrm{~nm}^{-1}, \mathrm{I}(q)$ exhibits a $q^{-m}$ dependence whatever the samples, with $m$ around 3.2. The $q$ domain in which it is measured suggests characteristic dimensions on the order of several hundreds of $\mathrm{nm}$. This could be the result of the agglomeration of nanodomains. They are however difficult to observe with AFM images, likely because their interface is diffuse, as suggested by the 3.2 $q$ slope. A small peak at $q$ ca. $1.2-1.5 \mathrm{~nm}^{-1}$ is visible, corresponding to a characteristic length around $4.2-5.2 \mathrm{~nm}$. Given the small height of this peak, such distance can be simply ascribed to the average distance between HS blocks[12] along the copolymer chains. Its small variation is consistent with the variation of the length of the HS (calculations detailed in SI). In agreement with AFM imaging, no characteristic distance is evidenced for PDMS-HMDI and PDMS-IPDI. In the case of PDMS-HDI and PDMS-TDI, additional shoulder is visible in the 0.2 to $0.4 \mathrm{~nm}^{-1} q$ range, which can be related (from a simplified fit of I $(q)$, cf. insert in Figure 4 (right), Figure 5, Figure S4, and fitting parameter in SI) to the distance deduced from AFM images ( $34 \mathrm{~nm}$ to compare to $20-30 \mathrm{~nm}$ for PDMS-HDI and $22 \mathrm{~nm}$ to compare to 15 - $20 \mathrm{~nm}$ for PDMS-TDI). Note that the deduced peak is much smaller for PDMS-TDI, which supports the idea of a weaker nanostructuration for this material compared to the two others.

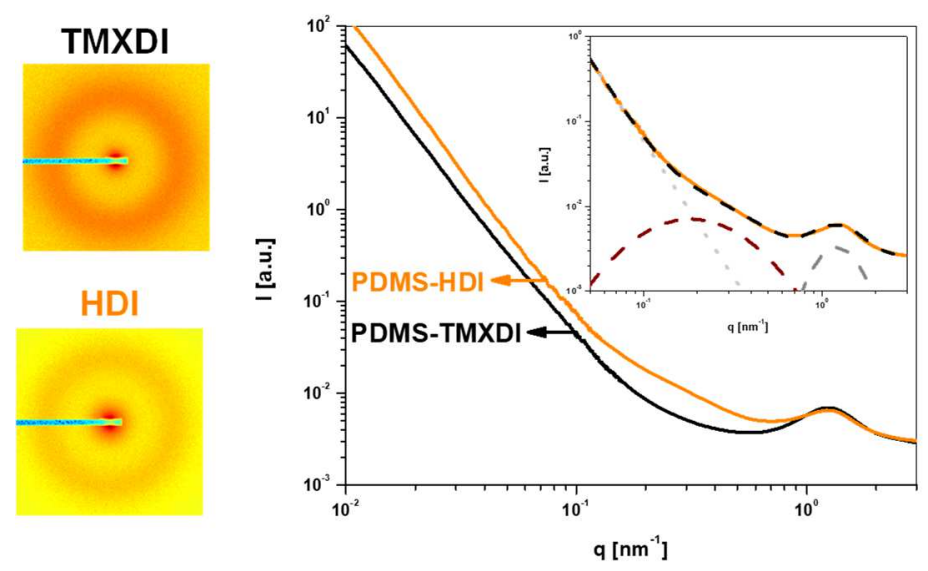

Figure 4: 2D (left) and 1D (right) patterns of combined SAXS/USAXS spectra obtained for PDMSTMXDI and PDMS-HDI. A fit of the PDMS-HDI data (dashed black curve) is presented in insert assuming the presence of a secondary correlation peak (dashed brown line), a $\mathrm{q}^{-3.3}$ slope in the $\mathrm{q}<0.3$ $\mathrm{nm}^{-1}$ range (dotted gray line) and a correlation peak of the HS blocks $\left(\mathrm{q}=1.23 \mathrm{~nm}^{-1}\right.$, dash gray line). 


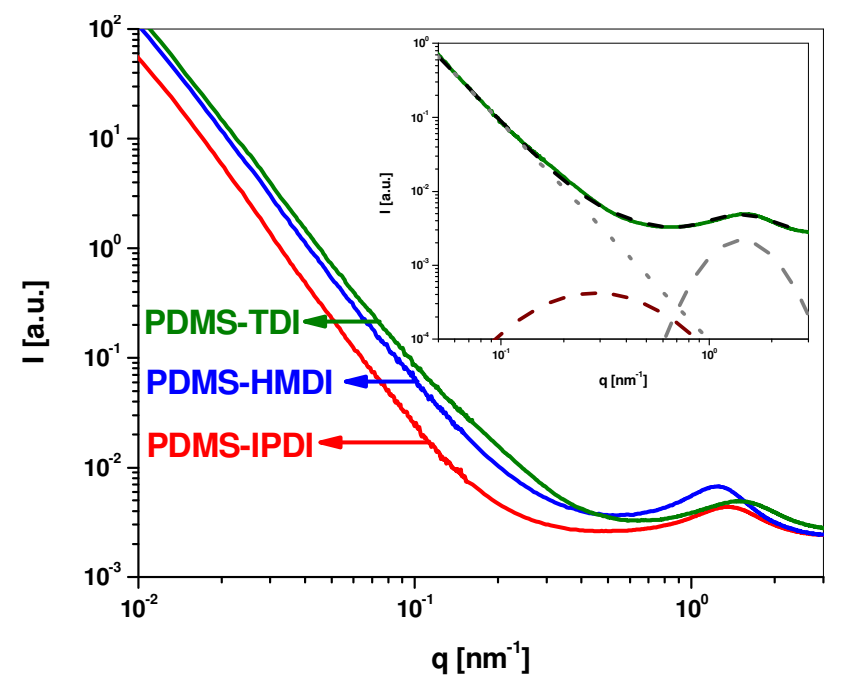

Figure 5: Combined SAXS/USAXS spectra obtained for PDMS-TDI, PDMS-HMDI and PDMS-IPDI. A fit of PDMS-TDI data (dashed black curve) is presented in insert.

Figure 6 presents the DSC curves obtained during consecutive heating and cooling ramps, under $\mathrm{N}_{2}$ atmosphere, for PDMS-TMXDI and PDMS-HDI. Both materials show peaks ascribed to melting and crystallization of the hard segments[26][27]. Two peaks are visible for PDMS-HDI, which indicates the presence of two crystalline populations. The total melting enthalpy deduced from the total area of these two peaks measured during the first heating ramp (black line, Figure $6 \mathbf{b}$ ) is around $2.4 \mathrm{~J} \mathrm{Jg}^{-1}$. The curves obtained during cooling (red line) and the second heating ramp show that both melting and crystallization phenomena are reversible, with roughly the same enthalpy (2.4 $\mathrm{J} \mathrm{g}^{-1}$ for both). The DSC analysis of a low molar mass model of the hard segment (bisurea-HDI, synthesis described in SI) was also performed (see Figure S5). A clear melting peak is observed at $105^{\circ} \mathrm{C}$, i.e. at a much higher temperature than for the corresponding silicone copolymer. This indicates the presence of much larger crystallites, as expected since the crystallization is not hindered by the presence of silicone segments. The melting enthalpy calculated from the peak area is around $98 \mathrm{J.g}^{-1}$. Within the assumption that most of the model bisureas have crystallized, and therefore assuming that this value corresponds to the specific melting enthalpy of the HDI crystal (note that this value necessarily underestimates the real one), one can deduce that ca. $29 \%$ of the hard segments have crystallized.

PDMS-TMXDI DSC curve (Figure 6a) shows a melting peak at a much higher temperature, around $155-175^{\circ} \mathrm{C}$. The melting enthalpy is also larger, ca. $7 \mathrm{~J} \mathrm{~g} \mathrm{~g}^{-1}$. The observed melting peak for the model bisurea-TMXDI is also measured at a much higher temperature $\left(212^{\circ} \mathrm{C}\right)$ than in presence of silicone soft segments (see Figure S5) and provides a minimum value of the melting enthalpy (69 J.g ${ }^{-1}$. With the same assumption as the one used for HDI, this would suggest that around $98 \%$ of the HS in the copolymer have crystallized. Although this value is an approximation it strongly suggests that a larger fraction of hard segments have crystallized in PDMS-TMXDI than in PDMS-HDI, which is consistent with the much larger modulus measured at ambient temperature for PDMS-TMXDI (see next section). Note that for this material, the DSC curves obtained during the first and the second heating ramps are very different. This poor reversibility of the melting-crystallization cycle is not ascribed to a slow kinetics of this process but to a degradation of the material at the temperature required to obtain the first complete melting of the material $\left(175^{\circ} \mathrm{C}\right)$. Such interpretation is supported by TGA measurements, performed at a faster heating rate $\left(10^{\circ} \mathrm{C} \cdot \mathrm{min}^{-1}\right)$, which show the beginning of a mass loss at $198^{\circ} \mathrm{C}$ (see Figure S6). DSC measurements have also been performed with the three other silicone-urea copolymers (i.e. PDMS-TDI, PDMS-HMDI, PDMS-IPDI) and do not reveal any endothermic or exothermic peaks (Figure S7b). 

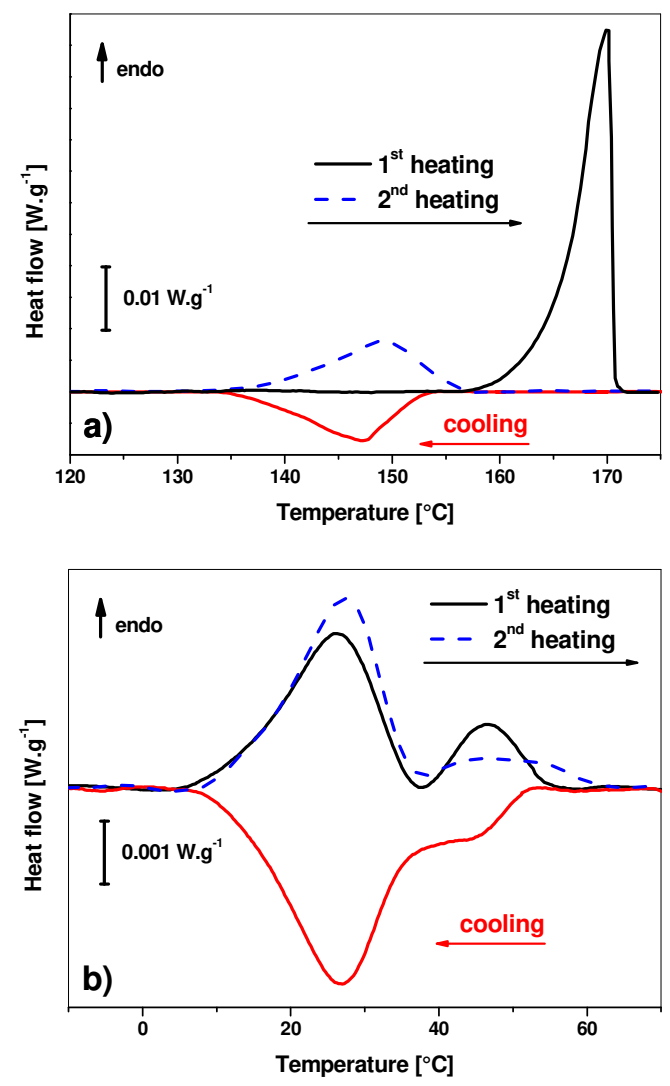

Figure 6: DSC curves from consecutive heating and cooling at $2^{\circ} \mathrm{C} \cdot \mathrm{min}^{-1}$ (under $\mathrm{N}_{2}$ flux) for a) PDMSTMXDI and b) PDMS-HDI (black: first heating scan, red: cooling scan, blue: second heating scan).

WAXS and SAXS experiments were also performed at different temperatures with the copolymers with asymmetric HS. The three samples show similar trends in the wide and small angle domains, and only results obtained for PDMS-TDI are displayed in Figure 7 (see Figure S8 for results on PDMS-HMDI and PDMS-IPDI). No significant evolution of the WAXS patterns is visible except a slight shift of the WAXS amorphous halo towards lower $q$ values. This halo is due to the scattering of the PDMS amorphous phase. The small variation of its position perfectly corresponds to the material thermal expansion estimated from the thermal expansion coefficient of the PDMS[28] (see Figure S9).

In the small angle domain, the increase in the temperature has a negligible influence on the exponent in the dependence of the scattered intensity with $q^{-m}$. Nevertheless, the temperature increase leads, for the 3 materials, to an increase of the scattered intensity in the $\left[0.2 \mathrm{~nm}^{-1} ; 2.5 \mathrm{~nm}^{-1}\right] q$ domain which can be reasonably ascribed to the dependence of the phase contrast on the temperature, as explained in SI. As expected, a slight shift of the peaks is also observed, very similarly to the one observed in WAXS with the PDMS amorphous peak, and is due to the thermal expansion. More interestingly, the shape of the peak tends to broaden toward low $q$ (Figure S10). For PDMS-TDI, the broadening is very weak and discernable at temperature above $130^{\circ} \mathrm{C}$. The broadening of the peak is slightly more important for the PDMS-HMDI and becomes visible at the same temperature $\left(130^{\circ} \mathrm{C}\right)$. For PDMS-IPDI, this temperature is lower, $110^{\circ} \mathrm{C}$, and the peak broadening is more pronounced. All these results indicate an evolution of the microstructure of the materials with temperature, reasonably ascribed to a decrease of the fraction of the associated hard phase segments. This evolution is however weak, the peak remaining clearly visible, particularly for the PDMS-TDI. 

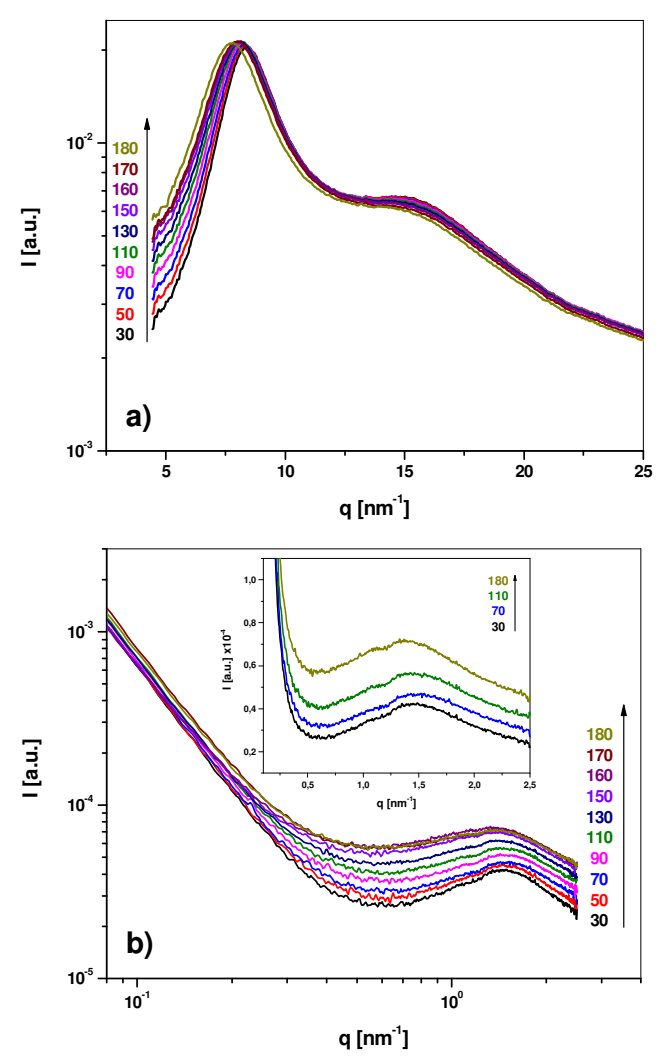

Figure $7:$ a) WAXS and b) SAXS spectra obtained for PDMS-TDI at different temperatures ranging from $30^{\circ} \mathrm{C}$ to $180^{\circ} \mathrm{C}$ (similar results obtained for PDMS-HMDI and PDMS-IPDI are reported in Figure S8).

\section{$\underline{3.2}$ Viscoelastic behavior}

Isochronal curves measured at $1 \mathrm{~Hz}$ during a heating step at $2^{\circ} \mathrm{C} \cdot \mathrm{min}^{-1}$ from $-50^{\circ} \mathrm{C}$ to $200^{\circ} \mathrm{C}$ are presented in Figure 8. In the low temperature domain, all the materials exhibit a plateau, which begins at the glass transition temperature of the materials[12], around $-120^{\circ} \mathrm{C}$ independently of the nature of the hard segments, (see Figure S7a); this temperature being close to the $T_{g}$ of PDMS[5], [13], [14] (note that given the low $T_{g}$ of PDMS, and the low fraction of HS, this is not sufficient to prove the strong immiscibility of the latter). The modulus value at this plateau should be the consequence of the presence of the mechanically effective crosslinks formed by both entanglements and associated hard segments with a dynamic frozen over the loading time. For PDMS-TDI, PDMS-HMDI and PDMS-IPDI, the E' value at this plateau is close to $5 \mathrm{MPa}$, whereas PDMS-HDI and PDMS-TMXDI exhibit a modulus of ca. 10 and ca. $18 \mathrm{MPa}$ respectively. In addition, one can notice for these samples an increase of the modulus with temperature in the low temperature part of the rubbery plateau. It was checked that this increase is fully reversible. It can be ascribed to entropic elasticity, since the crosslinks (either made of HS clusters or of trapped entanglements) can be considered as permanent compared to the loading time.

In the tested temperature domain, two modulus drops are observed for all the samples except PDMSTMXDI. For this latter, only one modulus drop is observed at $155^{\circ} \mathrm{C}$, which corresponds to the beginning of the melting phenomenon observed in DSC. In the same way, for PDMS-HDI the first modulus drop $\left(5-40^{\circ} \mathrm{C}\right)$ is concomitant with the first melting peak. The following smaller modulus drop $\left(40-60^{\circ} \mathrm{C}\right)$ is related to the second melting peak, which is also smaller than the first one. Thus, in PDMSHDI and PDMS-TMXDI, the melting phenomena observed in DSC have direct and visible consequences on the viscoelastic behavior. The other three PDMS, with asymmetrical HS, also show a first modulus decrease from the rubbery plateau (Figure 8b), even though it cannot be related to any melting 
endotherm. A second decrease of E' is observed at high temperature, with a crossing of the E' and E', curves indicating that the materials flow. This crossover is found at $164^{\circ} \mathrm{C}, 145^{\circ} \mathrm{C}$ and $122^{\circ} \mathrm{C}$ for PDMSTDI, PDMS-HMDI and PDMS-IPDI, respectively. A crossover is also observed for PDMS-HDI at $92^{\circ} \mathrm{C}$.
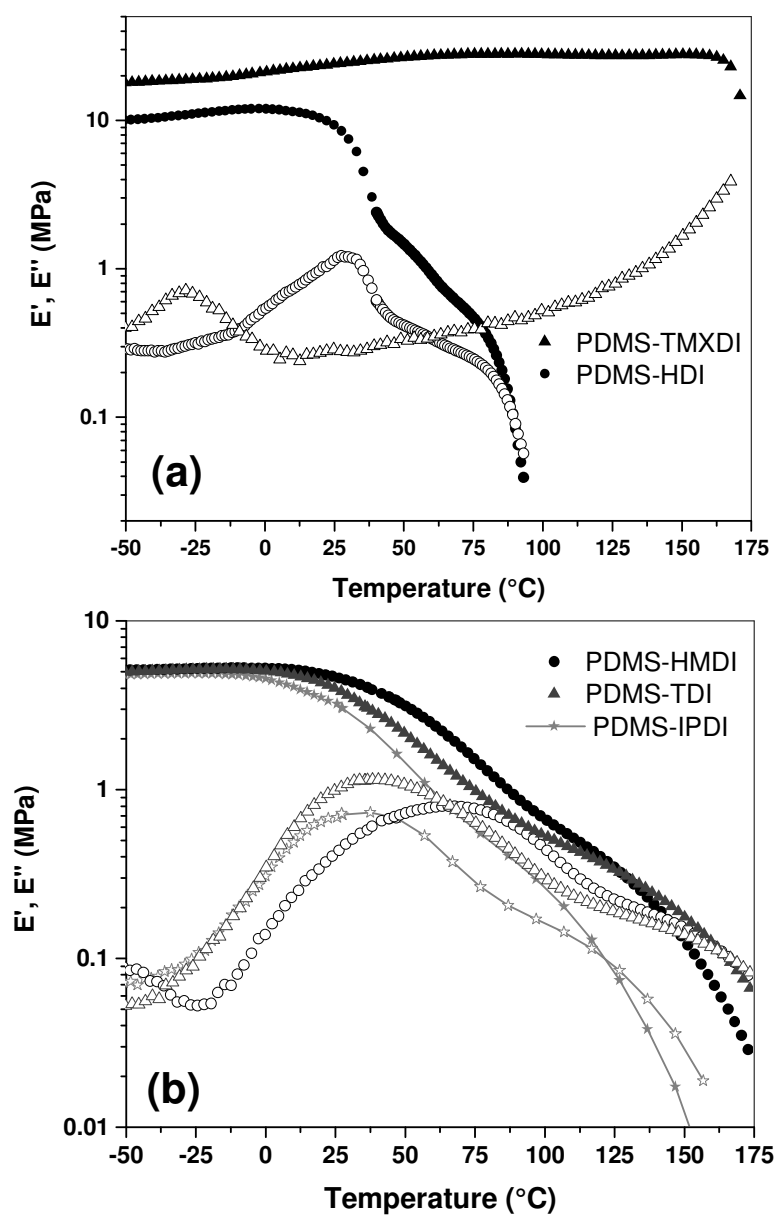

Figure 8: Combined DMA and rheological isochronal curves recorded at $2^{\circ} \mathrm{C} \cdot \mathrm{min}^{-1}$ and $1 \mathrm{~Hz}$. E' (filled symbols) and E" (unfilled symbols) as a function of temperature for (a) PDMS-TMXDI and PDMSHDI and (b) PDMS-TDI, PDMS-IPDI and PDMS-HMDI.

The rheological behavior of the materials was further characterized by frequency sweep measurements at different temperatures. Cole-Cole plots are reported in figure S12 and indicate a very good thermorheological simplicity. Thus, rheological master curves of PDMS-TDI, PDMS-HMDI and PDMS-IPDI can be built at a reference temperature of $30^{\circ} \mathrm{C}$ (Figure 9). As shown on this figure, time-temperature superposition works remarkably well, suggesting that no important microstructural modification occurs over the explored temperature domain. This confirms our previous conclusion established from the SAXS and WAXS performed at different temperatures. 


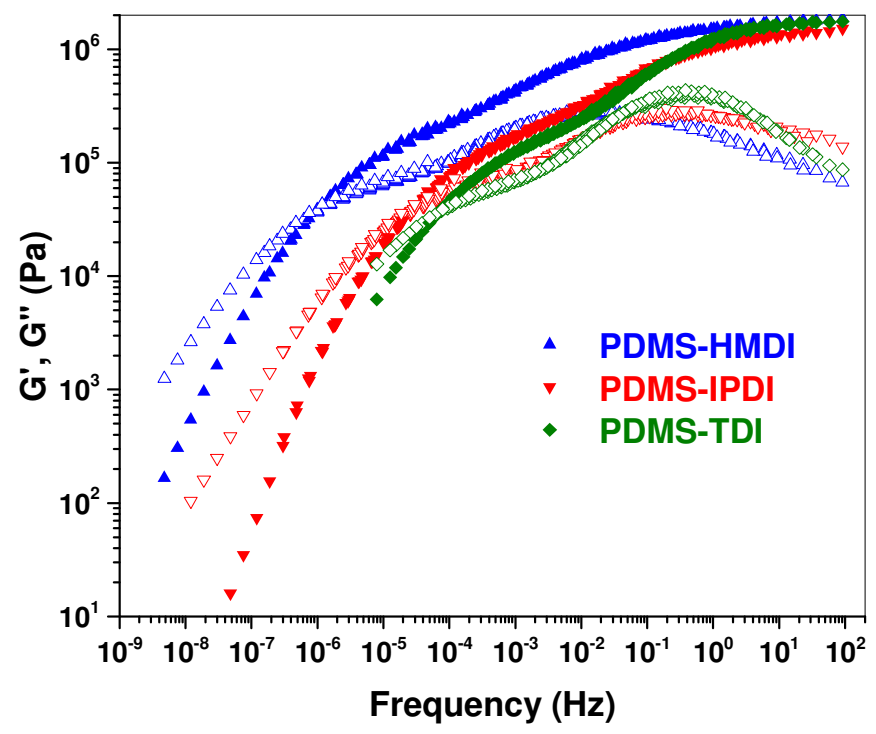

Figure 9: Linear viscoelastic master curves measured from shear rheology at a reference temperature of $30^{\circ} \mathrm{C}$. G' (filled symbols) and G" (unfilled symbols) as a function of the frequency.

Conversely, the Cole-Cole representation for PDMS-HDI displayed in figure S13 suggests a poor timetemperature superposition below $60^{\circ} \mathrm{C}$, explained by the crystallization process, which occurs at this temperature and below (Figure $6 \mathbf{b}$ ). This prevents any master curve building. Master curve was not performed either with PDMS-TMXDI as the temperature at which occurs the first modulus drop is close to the degradation temperature (see Figure S6).

Like the isochronal curves, the master curves of PDMS-TDI, PDMS-HMDI and PMDS-IPDI (Figure 9) show two relaxations, as commonly observed in entangled supramolecular polymer networks[29]. Conventionally, the relaxation observed at the highest frequency will be called hereafter $\alpha^{\prime}$ (since it is the relaxation phenomenon which occurs just after the $\alpha$ one). Note that the name of this relaxation can vary in the literature depending on the authors [30-32]. The second relaxation phenomenon, occurring at higher temperature, is called hereafter "terminal" (term. in abbreviated form).

The relaxation times deduced from the master curves build up are reported in Figure 10 The relaxation times $\tau_{\alpha}{ }^{\prime}(T)$ are estimated from the shift factors and the frequency at the maximum of the G" peak of the high frequency modulus drop, when measurable at the temperature of the frequency sweep measurement. $\tau_{\text {term }}(T)$ is calculated from the frequency at the G'/G' crossover of the isothermal curve at $160^{\circ} \mathrm{C}$ (cf. Figure S11). From the Arrhenius fitting of these relaxation times, an activation energy can be estimated. $E_{\alpha^{\prime}}$ is found equal to 78, 115 and $112 \mathrm{~kJ}^{\mathrm{mol}}{ }^{-1}$ for PDMS-TDI, PDMS-HMDI, and PDMSIPDI respectively. An activation energy can also be deduced for $\tau_{\text {term }}$ which is very close to the one deduced for the $\alpha$ ' process. The fact that roughly the same activation energy is found for both relaxational processes validates a posteriori, their plot on the same master curve. 


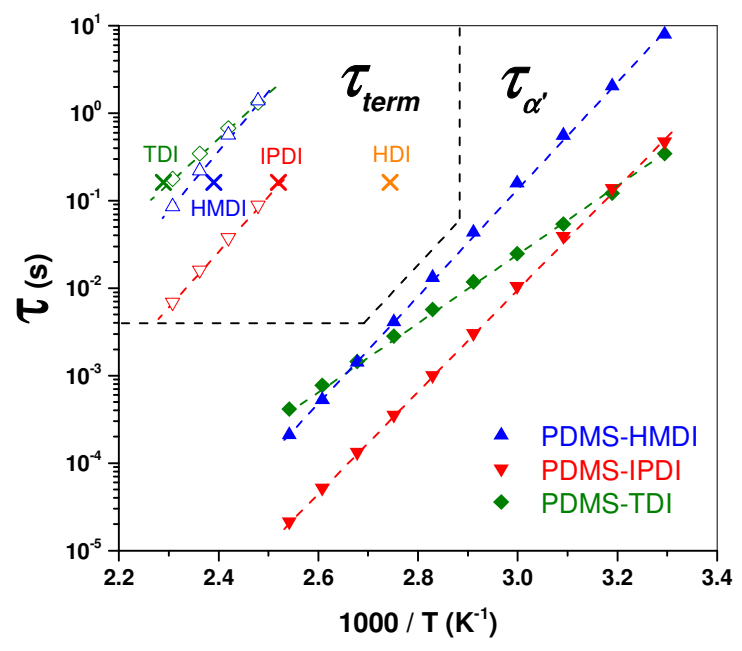

Figure 10: $\tau_{\alpha^{\prime}}$ (filled symbols) and $\tau_{\text {term }}$ (unfilled symbols) deduced from the isothermal curves as a function of 1000/T for PDMS-TDI, PDMS-HMDI and PDMS-IPDI. The relaxation times deduced from the isochronal curve $(\times$ symbols $)$ at $1 \mathrm{~Hz}$ of the three polymers and PDMS-HDI are also plotted as a proof of the validity of the master curve building.

\subsection{Nonlinear mechanical response}

The characterization of the non-linear mechanical response of the different materials is presented in Figure 11, All the materials show first a linear response from which a modulus can be deduced as reported in Table 2 Their value roughly corresponds to the storage modulus measured by DMA at $30^{\circ} \mathrm{C}$, and will be more deeply discussed in the discussion part. In addition, at larger strain, a rapid change in the slope is observed in the [0\%-10\%] strain domain. PDMS-TMXDI shows a short plateau followed by a rupture at a much smaller strain than the other samples. Moreover, before their rupture, the other materials show a hardening phenomenon, that is the most pronounced for PDMS-HMDI, and that decreases for PDMS-IPDI and even more for PDMS-HDI. PDMS-TDI does not show a significant hardening and seems to flow up to a strain at break much larger than for the other materials.

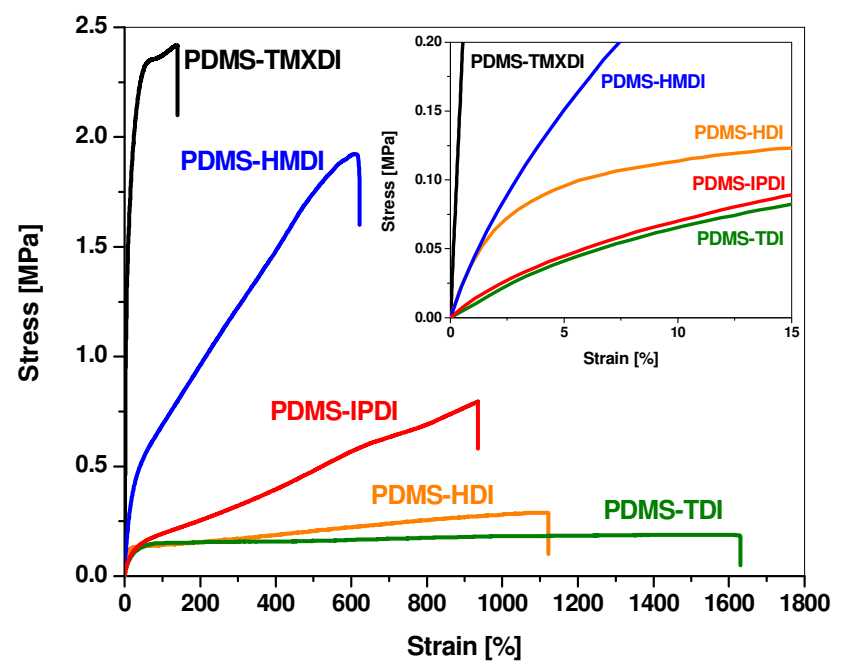

Figure 11: Tensile stress-strain curves of the five segmented silicone-urea copolymers. Insert: zoom at low percentage of deformation 
Table 2: Young modulus, stress and elongation at break from tensile tests performed on the different segmented silicone-urea copolymers.

\begin{tabular}{cccc}
\hline $\begin{array}{c}\text { Segmented silicone- } \\
\text { urea copolymers }\end{array}$ & $\begin{array}{c}\text { Young Modulus } \\
(\mathrm{MPa})\end{array}$ & $\begin{array}{c}\text { Stress at break } \\
(\mathrm{MPa})\end{array}$ & $\begin{array}{c}\text { Strain at break } \\
(\%)\end{array}$ \\
\hline PDMS-TMXDI & $35 \pm 2$ & $2.4 \pm 0,1$ & $200 \pm 30$ \\
PDMS-HDI & $4 \pm 0,2$ & $0.3 \pm 0,5$ & $1100 \pm 100$ \\
PDMS-TDI & $0.9 \pm 0,1$ & $0.2 \pm 0,02$ & $1600 \pm 100$ \\
PDMS-HMDI & $3.9 \pm 0,2$ & $2 \pm 0,1$ & $600 \pm 50$ \\
PDMS-IPDI & $1 \pm 0,1$ & $0.8 \pm 0,1$ & $900 \pm 80$ \\
\hline
\end{tabular}

\section{Discussion}

The above results show that the mechanical properties of the studied materials mainly depend on the nature of their HS rather than on the slight difference in their HS weight fraction (from 8.3 to $10.8 \mathrm{wt}$. $\%$ ). Same conclusion was also reported by Das et al.[33] with segmented TPU copolymers without chain extenders. Like in their work (in which the HS wt\% is however significantly higher) the choice of the HS has direct consequences on the material structuration. A phase separation with different morphologies is observed such as nodules in TMXDI-PDMS and filaments, more or less defined, in HDI-PDMS and TDI-PDMS. When crystallization of the core is possible, like in TMXDI and HDI, this structuration leads to significantly larger modulus in the temperature domain above their glass transition temperature. The crystallization is related to the symmetry of the core (as also shown by DFT calculations of Yildirim et al. [34]), which promotes a long range order as already reported in the literature for symmetrical hard segments in segmented copolymers with different soft segments such as PTMO[26], or PEG[27]. DSC analyses of bisurea-TMXDI and bisurea-HDI HS models (Figure S5) suggest that ca. $98 \%$ of the hard segments have crystallized in PDMS-TMXDI and that a significant part (ca. 29\%) of the HDI hard segments have also crystallized in PDMS-HDI. This large crystalline phase inhibits the material flow, even for long loading time, as far as the temperature remains below the melting temperature (Figure 6 and $7 \mathbf{a}$ ).

In the other materials, the hard segments do not crystallize, due to their asymmetry (for TDI and IPDI) or to the presence of three different isomers (for HMDI). A modulus plateau is however still observed, with a drop which therefore cannot be ascribed to any melting. It is related to the dynamics of the HSHS bonds, in the clusters they form. Thus, for low enough temperature or short enough loading, whether they crystallize or not, all the materials show a constant modulus, the difference being that it appears to be much higher in the two crystalline materials (with TMXDI and HDI). Note that in spite of a significant difference in modulus between a glassy phase and a crystallized one, at the same volume fraction, the mechanical reinforcement of a glassy and a crystallized dispersed phase is roughly equivalent in a very soft continuous phase such as a soft silicone (the modulus of a glassy or crystallized polymer being much larger than a rubbery one). Given the similar weight fraction of the hard segments in the different materials, the reason of the much larger modulus of PDMS-TMXDI or PDMS-HDI is therefore mainly due to their structuration at much larger scale (promoted by the nature of their HS core) compared to those of the materials with asymmetric HS core (as revealed by AFM and SAXS characterization). It is however difficult from the microstructural characterization to clearly identify what makes this structuration more mechanically efficient in PDMS-TMXDI. Moreover, AFM and SAXS also suggest the presence of filaments-like object in PDMS-TDI. Nevertheless this material has a significantly lower modulus in the plateau domain, which is consistent with the fact that these filaments seem much less defined, and likely made of disconnected small HS clusters.

Considering for this material (PDMS-TDI), like for PDMS-IPDI and PDMS-HMDI (in which no structuration was evidenced by AFM and SAXS), that HS clusters are formed of only few HS, it can be tempting to consider HS-HS bonds as crosslinks, i.e. as active stickers in the polymer chains. Assuming 
that a fraction $p$ of the HS associates and forms these crosslinks (which elastically link active silicone segments to form a network), the rubber elasticity theory for highly multifunctional nodes (the affine assumption is then appropriate and the Gaussian behavior of the chains is assumed) predicts for the rubbery modulus [29] [35]:

$$
E=3 \rho R T\left(\frac{p}{M_{s}}+\frac{1}{M_{e}}\right)\left(1-\frac{2 M_{s}}{M}\right) \quad \text { Equation } 1
$$

Where $M_{e}$ is the molar mass between entanglements, and $M_{s}$ the one between HS. With $M_{e}$ equal to 12000 g. $\mathrm{mol}^{-1}$ [36] (which is roughly half of $\mathrm{M}_{\mathrm{c}}$, the critical molar weight), and $\mathrm{M}_{\mathrm{s}}$ equal to $3250 \mathrm{~g} \cdot \mathrm{mol}^{-}$ ${ }^{1}$, assuming that all the HS are associated $(p=1), \mathrm{E}$ is found equal to $\sim 2.5 \mathrm{MPa}$. This value is lower than the one measured in Figure 8b, ca. 5MPa. This discrepancy by a 2 factor is obviously related to the fact that the HS clusters, in spite of their relatively small size, cannot be simply considered as connecting soft segments, but also form nanoscale reinforcing objects. Nevertheless, due to their size, they are much less mechanically efficient than the nanostructure formed by the HS clustering in PDMS-TMXDI or PDMS-HDI, as discussed above.

At sufficiently long time, or sufficiently high temperature, the dynamics of the HS bonds is fast enough to enable the material mechanical relaxation (leading to the so-called $\alpha$ ' relaxation). The excellent timetemperature superposition found for the 3 materials prove that the modulus drop is indeed the consequence of a relaxational process. This process both soften the existing HS clusters (which may be seen as a "glass transition" related process), and release the junctions points formed along the polymer chain by the HS-HS bonds. This is in agreement with the perfect reversibility of this drop with temperature. In other words, this drop does not need a modification of a structuration of the material, as shown by the SAXS experiments as a function of the temperature, in the temperature domain used to build the $\alpha$ ' relaxation master curve.

On isochronal curves (Figure 8) or on the master curves (Figure 9), the $\alpha$ relaxation leads to a modulus drop down to a value that can be estimated at the inflexion point of the E'(T) curves: it is found equal to ca. $0.8 \mathrm{MPa}$ for the three materials with non-symmetrical core, and also for the PDMS-HDI material. Such value is remarkably close to the modulus of an uncrosslinked entangled PDMS[36]. The temperature (at $1 \mathrm{~Hz}$ ) or the frequency (at $T_{\text {ref }}$ ) at which the modulus drops, depends on the nature of the hard segment (cf. Figure 8 and Figure 9). The thermally activated times - deduced from the master curve built up and reported on Figure 10 as a function of the inverse of the temperature - follow an Arrhenius behavior. In other words, they do not follow the WLF equation classically used for the $\alpha$ relaxation times of amorphous materials. Obviously, they are related to the HS-HS bond dynamics [5]. Nevertheless, they are larger by several orders of magnitude than the $\alpha$ ' relaxation time measured by dielectric measurements, this one being likely closer to the HS-HS association time.[29] This suggests that they also depends on the mobility in their vicinity[31], and in particular that they may be closely related to the $\alpha$ relaxation time $\tau_{\alpha}$ of the PDMS segments. Thus, inspired by Chen et al. work, it is tempting to use the following equation, which implicitly neglect the presence of large HS clusters, (or in other words, consider that these clusters are made of a limited number of HS-HS associations):

$$
\frac{\tau_{\alpha \prime}(T)}{\tau_{\alpha}(T)}=A e^{-\frac{E_{\text {diss }}}{R T}} \quad \text { Equation } 2
$$

where $E_{\text {diss }}$ is the activation energy of the HS dissociation and A a constant. Given the high temperature explored by DMA compared to the glass transition temperature of the materials (ca. $-120^{\circ} \mathrm{C}$, i.e. equal to that of PDMS), $\tau_{\alpha}$ only slightly varies in this domain and should be considered roughly constant in the range of the Debye time $10^{-12} \mathrm{~s}$. The Arrhenius plot (Figure 10) therefore enables to find $E_{\text {diss }}$

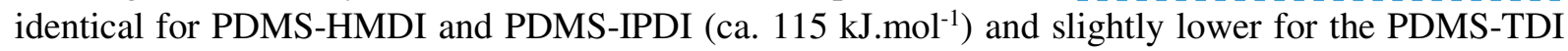
(ca. $78 \mathrm{~kJ} . \mathrm{mol}^{-1}$ ). Such values can be compared to the energy of bidentate urea hydrogen bonding, proposed by Yilgor et al., i.e. $58.5{\mathrm{~kJ} . \mathrm{mol}^{-1}}^{\text {[9] }}$. The hard segments of the three materials indeed contain 
two urea groups, which can form this type of bonds. The $E_{\text {diss }}$ values found for PDMS-HMDI and PDMSIPDI are therefore consistent with this interpretation. The lower value of $E_{\text {diss }}$ for PDMS-TDI suggests that the formation of bidentate bonds in this material is more difficult. Such interpretation is however in contradiction with literature that suggests that TDI based bisureas associate by forming 4 hydrogen bonds, [37] whereas in HMDI and IPDI based bisureas, the two ureas probably have independent orientations, i.e. hydrogen bonds are formed 2 by 2 instead of 4 by 4 . One explanation for this discrepancy may be that the presence of the soft segments in the vicinity of the HS could perturb the way they associate (limiting the association of the two urea groups in the case of TDI and conversely promoting it with HMDI and IPDI). Nevertheless, another more reasonable explanation may be the empirical character of the Arrhenius law used in equation 2. In particular, it must be recalled that the meaning of the pre-exponential factor A is physically unclear. Found around $10^{-2}$ for TDI, it is much lower for HMDI $\left(10^{-5}\right)$ and found as low as $10^{-9}$ for IPDI. Often related to activation entropy (the lower it is, the larger this entropy term), it suggests that the $\alpha$ ' relaxational mechanism is the result of complex molecular processes, especially for IPDI and for HMDI. Therefore, the deduced value of the activation energy for these materials cannot be easily and simply related to the urea bond dissociation.

In the temperature range explored to build a master curve for the second modulus drop, SAXS measurements indicate a slight modification with temperature of the peak ascribed to the distance between associated hard segments domains. However, this variation is seemingly too small to prevent a very good time temperature equivalence. Like for the $\alpha$ ' process, this suggests that this second modulus drop is also mainly the result of a relaxational process. The slopes of G' and G' in Figure 9 tend, at the highest temperatures, toward 1 and 2 respectively, which clearly indicates that the polymer flows. The relaxation times, $\tau_{\text {term }}$, deduced from the building of the master curves also follows an Arrhenius law (Figure 10) with activation energies very close to the ones of the $\alpha$ ' process. Both processes are therefore strongly related. This obviously raises some questions. The study of Buckwalter et al. [21], on a material very similar to our PDMS-TDI, supported the idea of the concomitance of the loss of the nanostructuration, with the material flow. As said previously, our SAXS/WAXS experiments versus temperature on PDMS-TDI, PDMS-HMDI and PDMS-IPDI (Figure 7 Figure S8 and Figure S10) only show a weak evolution of the scattering function. In particular, it shows a small broadening of the peak characteristic of the distance between hard segments, more or less pronounced, depending on the nature of the hard segments. These slight variations, almost insignificant for PDMS-TDI, and more significant for the two other materials, may be commented with FTIR results (see Figure S14), that show the relative evolution of the amount of hydrogen bonded carbonyl groups with temperature. The fraction of bonded $\mathrm{C}=\mathrm{O}$ is roughly constant for PDMS-TDI up to $160^{\circ} \mathrm{C}$, but, for PDMS-HMDI, it rapidly decreases above $150^{\circ} \mathrm{C}\left(30 \%\right.$ variation over $\left.50^{\circ} \mathrm{C}\right)$, and it decreases significantly above $110^{\circ} \mathrm{C}$ for PDMS-IPDI (with a relative decrease of around $40 \%$ over $100^{\circ} \mathrm{C}$ ). FTIR provides an instantaneous picture of the system, in which the measured quantity of bonded $\mathrm{C}=\mathrm{O}$ is the result of the ratio of the association time by the dissociation time. It is therefore not surprising that the FTIR results are correlated with the SAXS observation: a loss of structuration and therefore of phase separation should increase the distance between HS domains and therefore the dissociation time. This should promote a decrease of the ratio of the association to the dissociation time. Thus, the time temperature equivalence clearly appears to be an approximation when it is used for the master curve build up of PDMS-IPDI, and to a lesser extent, for the master curve build up of PDMS-HMDI. Nevertheless, the decrease of the number of associated hard segment does not inhibit a good TTS because this decrease is slow over the large temperature domain explored. This does not either challenge the existence of a terminal relaxation at low temperature for PDMS-IPDI and PDMS-HMDI, as shown by the master curves at $T_{r e f}=30^{\circ} \mathrm{C}$ on Figure 9: the examination of the frequency sweep measurements is indeed convincing. More importantly, crack healing tests at $50^{\circ} \mathrm{C}$, (i.e. at a temperature which does no lead to any significant microstructural modification), shows a crack disappearance after $15 \mathrm{~h}$, proving that these material can experience a terminal relaxation at this temperature (see Figure S15 in supplementary information). 
Therefore, one can try to apply the theory of supramolecular dynamics of polymer chains, usually applied to copolymers with dimer forming stickers; i.e. in absence of nanostructuration. This theory predicts the following relation between $\tau_{\text {term }}$ and $\tau_{\alpha}$ :

$$
\frac{\tau_{\text {term }}}{\tau_{\alpha^{\prime}}} \simeq \frac{\mathrm{N}^{3}}{\mathrm{~N}_{\mathrm{e}} \mathrm{N}_{\mathrm{S}}^{2}}=\frac{\mathrm{M}^{3}}{\mathrm{M}_{\mathrm{e}} \mathrm{M}_{\mathrm{S}}^{2}} \quad \text { Equation } 3
$$

with $N$ the number of dimethyl-siloxane monomers of the polymer chain, related to its molar mass $M$, $N_{e}$ the number of monomers between entanglement (related to $M_{e}$ ) and $N_{s}$ the number of monomers between HS. Given the polydispersity index around 2 for all the materials, $\tau_{\text {term }}$ should be spread over more than one decade; this is consistent with the quite large terminal relaxation observed on Figure 9 , Using $M_{n}\left(M_{w}\right)$ to calculate $N$, equation (3) leads to a $\tau_{\text {term }} / \tau_{\alpha^{\prime}}$ ratio of ca.1400 (5600 found with $M_{w}$ ), ca. 900 (5300) and ca. 1400 (8400) for PDMS-TDI, PDMS-HMDI and PDMS-IPDI, respectively. This ratio is in the same range as the experimental ones, found equal to ca. 3300, 6800 and 4300 for PDMS-TDI, PDMS-HMDI and PDMS-IPDI, respectively. This is positively remarkable given the approximation of the theory (no nanostructuration at all), and the uncertainty in the estimation of $\tau_{\alpha^{\prime}}$ (here at the maximum of G', when it may be estimated from the beginning of the G' decrease). This supports our interpretation that the terminal relaxation is related to the dynamics of the HS-HS dissociation, as schematized in Figure 12.

As said previously, it is impossible to accurately characterize a terminal relaxation of the PDMSTMXDI material since it degrades at the temperature at which relaxation should occur. In the case of PDMS-HDI, the crystal melting is at a temperature too high to enable the correct use of time-temperature equivalence with the isothermal DMA data. However, the temperature at which the terminal relaxation occurs at $1 \mathrm{~Hz}$ can be deduced from the DMA isochronal curve (at $1 \mathrm{~Hz}$ ). For this material, $\tau_{\text {term }}$ is equal to $0,16 \mathrm{~s}$ at $90^{\circ} \mathrm{C}$. Such a value can be added on Figure 10. At this temperature, by extrapolating the Arrhenius plot of PDMS-IPDI, its $\tau_{\text {term }}$ value is found 40 times larger than the one of PDMS-HDI. Applying the same method as previously (equation (3)), one should find for PDMS-HDI a $\tau_{\text {term }} / \tau_{\alpha^{\prime}}$ ratio of 960 (5600). This result means that $\tau_{\alpha^{\prime}}$ of HDI may be between 25000 and 170000 smaller than $\tau_{\text {term }}$ of IPDI, i.e. significantly smaller than $\tau_{\alpha^{\prime}}$ of IPDI. This material having the smallest $\tau_{\text {term }}$ of the three materials with non-symmetric core, our results suggest that at $90^{\circ} \mathrm{C}$, its $\tau_{\alpha^{\prime}}$ value is the lowest, or in other words that the HS-HS bonds in HDI, when not organized in crystals, may be the most dynamic. The activation energy of $\tau_{\alpha^{\prime}}$ being a priori in the range of $110 \mathrm{~kJ} \mathrm{~mol}^{-1}$, given the structure of the HDI core (aliphatic carbon chain between hydrogen bonds), one may reasonably extend this conclusion to all temperatures.

The tensile behavior of the different samples (at the tested temperature) is consistent with the previous analysis of their viscoelastic behavior, especially with the results of Figure 9 and Figure 10. PDMSTMXDI and PDMS-HDI having a crystallized phase, their stress-strain curves show a pseudo-plastic threshold. This one is high for PDMS-TMXDI as it contains well-structured crystalline phase at large scale. It is lower in PDMS-HDI, as the structuration of its crystallized phase is less mechanically efficient, and because a significant part of this phase has molten at the temperature of the tensile tests (cf. Figure 6). In PDMS-TMXDI materials, the presence of a crystallized phase and of its nanostructuration also explains the rapid hardening, interrupted by a rupture of the material due to the large stress level they lead to. Conversely, PDMS-HDI shows a weak hardening, even smaller than IPDI material, which can be related to the previous discussion on the rapid dynamics of its associative bonds (its $\tau_{\text {term }}$ being likely smaller than the one of PDMS-IPDI).

Regarding the 3 materials with the non-symmetrical cores, their tensile curves (cf. Figure 11) are also consistent with the DMA analysis, their behavior at low strain being related to the $\alpha$ ' relaxation whereas the behavior at large strain can be explained by their terminal relaxation. Thus, $\tau_{\alpha^{\prime}}$ larger for PDMSHMDI leads to a larger Young modulus, close to the one measured in DMA ( $\tau_{\alpha^{\prime}}$ is around $10 \mathrm{~s}$, in the same range as the time needed to reach $10 \%$ strain, ca. 20s, cf. Figure 10). The smaller $\tau_{\alpha^{\prime}}$ for PDMS- 
IPDI and PDMS-TDI leads to a rapidly non-linear behavior and therefore to an estimated Young modulus smaller than the storage modulus measured in DMA at ambient temperature. These two materials having at $30^{\circ} \mathrm{C}$ a quasi-identical $\tau_{\alpha}$, it is not surprising that they lead to the same Young modulus estimate. Moreover, an extrapolation of the relaxation time curves at $30^{\circ} \mathrm{C}$ (see Figure S16), suggests that $\tau_{\text {term }}$ of PDMS-HMDI is much larger than the one of PDMS-IPDI (40 times larger), or of PDMS-TDI, and close to the time of the tensile test experiment. This is consistent with the strongest hardening observed for this material. The extrapolated $\tau_{\text {term }}$ of PDMS-TDI being the smallest, this material shows almost no hardening. Finally, the elongation at break appears to be strongly correlated to the ability of the materials to flow, i.e. inversely correlated to the hardening they show at large deformation.

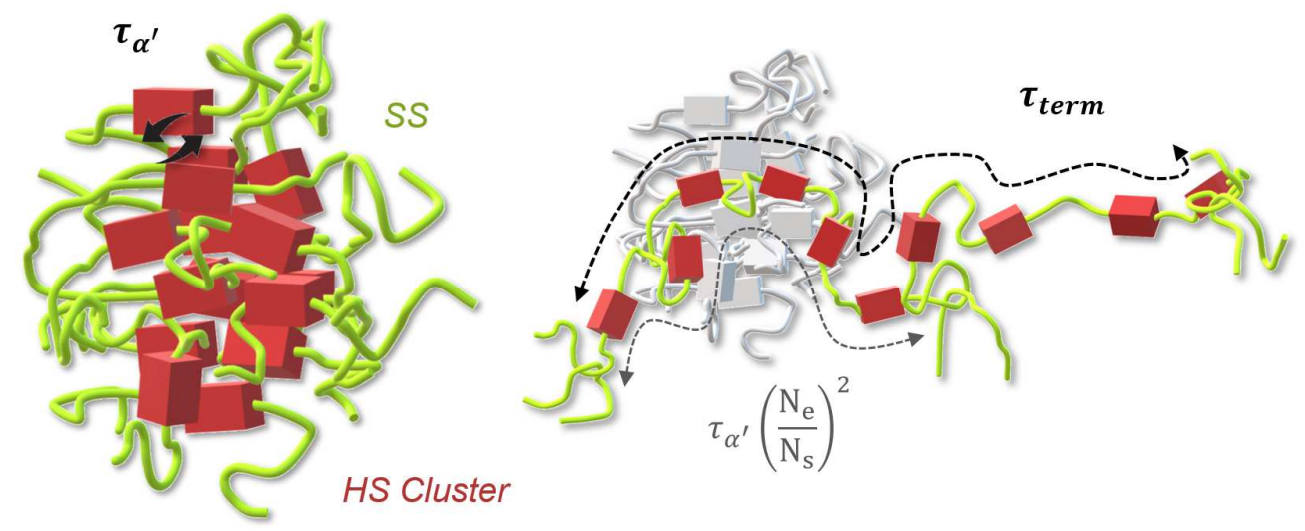

Figure 12: Scheme of the relaxationnal mechanisms in the segmented silicone copolymer with asymmetric HS. Depending on the HS segments nature, HS clustering is more or less important (AFM suggesting that clusters are smaller in PDMS-IPDI and PDMS-HMDI).

\section{Conclusion:}

By comparing the characteristics of segmented silicone copolymers, which differ by the nature of their urea hard segments, we have confirmed that the choice of symmetrical or non-symmetrical HS is a critical parameter to drive the microstructure and the viscoelastic behavior of the material. Due to the very different chemical characteristics of the soft (silicone) and hard segments, some phase separation always occurs at the nanometric scale (HS clustering). When the hard segments are non-symmetrical (and introduced like here at a relatively low weight fraction), the materials are weakly nanostructured. Structuration has therefore a limited impact on the mechanical response, which is then mainly controlled by the association dynamics of the HS-HS bonds. Thus, at long time, the material can flow, although the flow time is increased by a factor of several decades because of the presence of the HS-HS bonds which create dynamic crosslinks along the polymer chains (the characteristic time is for instance above 4 months for PDMS-HMDI). The obtained materials combine the behavior of an elastomer with the one of a thermoplastic material whose temperature domain (at fixed frequency), or the frequency domain (at fixed temperature) of the rubbery plateau would be very largely spread. These materials can therefore 
flow under stress, and crack healing (by flow) is possible at long time. When the HS are symmetrical, their self-organization, which is due to the intermolecular hydrogen bonding between the urea groups, is favored and the long range ordering of these associative core is possible. In the organized phase, the sticker dynamics is frozen at temperatures up to the melting temperature. The behavior of these materials is therefore close to the one of a semi-crystalline material, with a melting temperature very far from the glass transition of the amorphous silicone polymer and with a low crystallinity (due to the low fraction of hard segments). Hence, their flow (and therefore their self-healing) is only possible at temperatures above the melting temperature. This flow also depends on the HS-HS bonds dynamics, which is found to be the most rapid with the HDI core.

To conclude, soundly based on previous works from the literature, the present study has implemented an approach combining various and very complementary techniques of microstructural and mechanical characterization on 5 model systems based on PDMS-urea segmented copolymers. By playing on the chemical structure and nature of the HS, it appears interesting to limit their ability to crystallize (using an asymmetrical chemical structure) while maintaining high enough density of HS, with dynamics sufficiently slow to ensure the elastomeric properties of the material, and sufficiently rapid to allow selfhealing at moderate temperature and time. Several strategies should be evaluated and will be considered in further studies: in a first option, the mechanical properties of the copolymers can be modulated with crystalline HS, by adding molecules limiting the inter H-bonding in order to decrease their crystallinity; reinforcing nanofillers can also be added in copolymers with asymmetrical HS in order to increase their stiffness while keeping a sufficient dynamics of the HS-HS bonds.

\section{Acknowledgements}

This work was supported by the French Agence Nationale de la Recherche (project ANR-15-CE080022 Arcade).

The WAXS data was recorded on the WOS detector which was funded by the French National Research Agency (ANR) under the "Investissements d'avenir" program with the grant number: ANR11-EQPX-0010. The authors are indebted to Dr. Isabelle Morfin, our local contact at ESRF, for assistance in the experiments on the D2AM line. We are also indebted to Dr. F. Rousset for his precious support for the rheology experiments.

The authors would like to thank:

- the "Microstructure Technological Center" (CT $\mu)$ of University of Lyon for the access to the ultramicrotome.

- $\quad$ CLYM (www.clym.fr) for the access to their AFM device.

\section{References}

[1] W. Noll, Chemistry and Technology of Silicones, Academic press, New York, 1968.

[2] S.J. Clarson, J.A. Stephen, Siloxane polymers, Prentice Hall, Englewood Cliffs (New Jersey), 1993.

[3] I. Yilgör, J.S. Riffle, G.L. Wilkes, J.E. McGrath, Siloxane-urea segmented copolymers - 1. Synthesis and characterization of model polymers from MDI and $\alpha, \omega-$ bis(aminopropyl)polydimethylsiloxane, Polym. Bull. 8 (1982) 535-542. https://doi.org/10.1007/BF00262932.

[4] I. Yílgor, A.K. Sha'aban, W.P. Steckle, D. Tyagi, G.L. Wilkes, J.E. McGrath, Segmented organosiloxane copolymers. 1. Synthesis of siloxane-urea copolymers, Polymer (Guildf). 25 
(1984) 1800-1806. https://doi.org/10.1016/0032-3861(84)90254-4.

[5] I. Yilgor, E. Yilgor, Silicone containing copolymers: Synthesis, properties and applications, Prog. Polym. Sci. 39 (2014) 1165-1195. https://doi.org/10.1016/j.progpolymsci.2013.11.003.

[6] E. Yilgor, I. Yilgor, Hydrogen bonding: A critical parameter in designing silicone copolymers, Polymer (Guildf). 42 (2001) 7953-7959. https://doi.org/10.1016/S0032-3861(01)00293-2.

[7] J. Brandrup, E.H. Immergut, E.A. Grulke, Polymer handbook, fourth edition, John Wiley \& Sons, New York, 1999.

[8] I. Yilgor, E. Yilgor, Structure - Morphology - Property Behavior of Segmented Thermoplastic Polyurethanes and Polyureas Prepared without Chain Extenders Structure-MorphologyProperty Behavior of Segmented Thermoplastic Polyurethanes and Polyureas Prepared without Chain Extende, Polym. Rev. 47 (2007) 487-510. https://doi.org/10.1080/15583720701638260.

[9] E. Yılgor, I. Yılgor, E. Yurtsever, Hydrogen bonding and polyurethane morphology . I . Quantum mechanical calculations of hydrogen bond energies and vibrational spectroscopy of model compounds, Polymer (Guildf). 43 (2002) 6551-6559.

[10] S. Sami, E. Yildirim, M. Yurtsever, E. Yurtsever, E. Yilgor, I. Yilgor, G.L. Wilkes, Understanding the influence of hydrogen bonding and diisocyanate symmetry on the morphology and properties of segmented polyurethanes and polyureas : Computational and experimental study, Polymer (Guildf). 55 (2014) 4563-4576. https://doi.org/10.1016/j.polymer.2014.07.028.

[11] E. Yildirim, M. Yurtsever, E. Yurtsever, I. Yilgor, E. Yilgor, Multiscale Modeling of the Morphology and Properties of Segmented Silicone-Urea Copolymers, J. Inorg. Organomet. Polym. Mater. 22 (2012) 604-616. https://doi.org/10.1007/s10904-011-9588-1.

[12] D. Tyagi, I. Yílgör, J.E. McGrath, G.L. Wilkes, Segmented organosiloxane copolymers: 2 Thermal and mechanical properties of siloxane-urea copolymers, Polymer (Guildf). 25 (1984) 1807-1816. https://doi.org/10.1016/0032-3861(84)90255-6.

[13] D. Tyagi, G.L. Wilkes, I. Yilgör, J.E. McGrath, Siloxane-urea segmented copolymers - 2. Investigation of mechanical behavior, Polym. Bull. 8 (1982) 543-550. https://doi.org/10.1007/BF00262933.

[14] A.M. Stricher, R.G. Rinaldi, C. Barrès, F. Ganachaud, L. Chazeau, How I met your elastomers: from network topology to mechanical behaviours of conventional silicone materials, RSC Adv. 5 (2015) 53713-53725. https://doi.org/10.1039/C5RA06965C.

[15] O. Colombani, C. Barioz, L. Bouteiller, C. Chane, L. Fompérie, F. Lortie, H. Montès, Attempt toward 1D Cross-Linked Thermoplastic Elastomers : Structure and Mechanical Properties of a New System, Macromolecules. 38 (2005) 1752-1759. https://doi.org/10.1021/ma048006m.

[16] L.R. Hart, J.L. Harries, B.W. Greenland, H.M. Colquhoun, W. Hayes, Healable supramolecular polymers, Polym. Chem. 4 (2013) 4860-4870. https://doi.org/10.1039/c3py00081h.

[17] L. Leibler, P. Cordier, C. Soulie, Self-healing and thermoreversible rubber from supramolecular assembly, Nature. 451 (2008) 977-980. https://doi.org/10.1038/nature06669.

[18] B.J. Blaiszik, S.L.B. Kramer, S.C. Olugebefola, J.S. Moore, N.R. Sottos, S.R. White, Selfhealing polymers and composites, Annu. Rev. Mater. Res. 40 (2010) 179-211. https://doi.org/10.1179/095066010X12646898728408.

[19] I. Yilgor, T. Eynur, E. Yilgor, G.L. Wilkes, Contribution of soft segment entanglement on the tensile properties of silicone-urea copolymers with low hard segment contents, Polymer (Guildf). 50 (2009) 4432-4437. https://doi.org/10.1016/j.polymer.2009.07.016.

[20] E. Yilgor, G.E. Atilla, A. Ekin, P. Kurt, I. Yilgor, Isopropyl alcohol : an unusual, powerful, ‘ 
green ' solvent for the preparation of silicone - urea copolymers with high urea contents, Polymer (Guildf). 44 (2003) 7787-7793. https://doi.org/10.1016/j.polymer.2003.10.048.

[21] D.J. Buckwalter, M. Zhang, D.L. Ingle, R.B. Moore, T.E. Long, Synthesis and characterization of siloxane-containing poly ( urea oxamide ) segmented copolymers, Polymer (Guildf). 54 (2013) 4849-4857. https://doi.org/10.1016/j.polymer.2013.07.025.

[22] D.B. Klinedinst, E. Yilgör, I. Yilgör, F.L. Beyer, J.P. Sheth, G.L. Wilkes, Structure-Property Behavior of New Segmented Polyurethanes and Polyureas Without Use of Chain Extenders, Rubber Chem. Technol. 78 (2005) 737-753.

[23] S. Nozaki, S. Masuda, K. Kamitani, K. Kojio, A. Takahara, G. Kuwamura, D. Hasegawa, K. Moorthi, K. Mita, S. Yamasaki, Superior Properties of Polyurethane Elastomers Synthesized with Aliphatic Diisocyanate Bearing a Symmetric Structure, (2017). https://doi.org/10.1021/acs.macromol.6b02044.

[24] J.P. Sheth, A. Aneja, G.L. Wilkes, E. Yilgor, G.E. Atilla, I. Yilgor, F.L. Beyer, Influence of system variables on the morphological and dynamic mechanical behavior of polydimethylsiloxane based segmented polyurethane and polyurea copolymers : a comparative perspective, Polymer (Guildf). 45 (2004) 6919-6932. https://doi.org/10.1016/j.polymer.2004.06.057.

[25] S.D. Seneker, L. Born, H.G. Schmelzer, C.D. Eisenbach, K. Fischer, Diisocyanato dicyclohexylmethane : structure / property relationships of its geometrical isomers in polyurethane elastomers, Colloid Polym. Sci. 270 (1992) 543-548.

[26] S. Das, I. Yilgor, E. Yilgor, B. Inci, O. Tezgel, F.L. Beyer, G.L. Wilkes, Structure-property relationships and melt rheology of segmented, non-chain extended polyureas: Effect of soft segment molecular weight, Polymer (Guildf). 48 (2007) 290-301. https://doi.org/10.1016/j.polymer.2006.10.029.

[27] M.A. Hood, B. Wang, J.M. Sands, J.J. La Scala, F.L. Beyer, C.Y. Li, Morphology control of segmented polyurethanes by crystallization of hard and soft segments, Polymer (Guildf). 51 (2010) 2191-2198. https://doi.org/10.1016/j.polymer.2010.03.027.

[28] J.E. Mark, Polymer data handbook, Oxford University Press, 1999.

[29] Z. Zhang, Q. Chen, R.H. Colby, Dynamics of associative polymers, Soft Matter. (2018). https://doi.org/10.1039/C8SM00044A.

[30] B.J. Gold, C.H. Hövelmann, N. Lühmann, A. Wischnewski, D. Richter, The microscopic origin of the rheology in supramolecular entangled polymer networks, J. Rheol. (N. Y. N. Y). 61 (2017) 1211-1225.

[31] M. Ahmadi, L.G.D. Hawke, H. Goldansaz, E. Van Ruymbeke, Dynamics of Entangled Linear Supramolecular Chains with Sticky Side Groups : Influence of Hindered Fluctuations, Macromolecules. 48 (2015) 7300-7310. https://doi.org/10.1021/acs.macromol.5b00733.

[32] Q. Chen, Z. Zhang, R.H. Colby, Viscoelasticity of entangled random polystyrene ionomers, J. Rheol. (N. Y. N. Y). 60 (2017) 1031-1040. https://doi.org/10.1122/1.4955432.

[33] S. Das, D.F. Cox, G.L. Wilkes, D.B. Klinedinst, E. Yilgor, F.L. Beyer, S. Das, D.F. Cox, G.L. Wilkes, D.B. Klinedinst, E. Yilgor, F.L. Beyer, H. Strength, D.B. Klinedinst, I. Yilgor, Effect of Symmetry and H - bond Strength of Hard Segments on the Structure - Property

Relationships of Segmented, Nonchain Extended Polyurethanes and Polyureas, J. Macromol. Sci. Part B Phys. 46 (2007) 853-875. https://doi.org/10.1080/00222340701388805.

[34] E. Yildirim, M. Yurtsever, The role of diisocyanate and soft segment on the intersegmental interactions in urethane and urea based segmented copolymers: A DFT study, Comput. Theor. Chem. 1035 (2014) 28-38. https://doi.org/10.1016/j.comptc.2014.02.021. 
[35] L. Leibler, M. Rubinstein, R.H. Colby, Dynamics of Reversible Networks, Macromolecules. 24 (1991) 4701-4707. https://doi.org/10.1021/ma00016a034.

[36] L.J. Fetters, D.J. Lohse, R.H. Colby, Chain Dimensions and Entanglement Spacings, in: J.E. Mark (Ed.), Phys. Prop. Polym. Handb. 2e Ed., Springer, New York, 2006: pp. 445-452.

[37] P. Brocorens, M. Linares, C. Guyard-Duhayon, R. Guillot, B. Andrioletti, D. Suhr, B. Isare, R. Lazzaroni, L. Bouteiller, Conformational Plasticity of Hydrogen Bonded Bis-urea Supramolecular Polymers, J. Phys. Chem. B. 117 (2013) 5379-5386. 
For table of content only
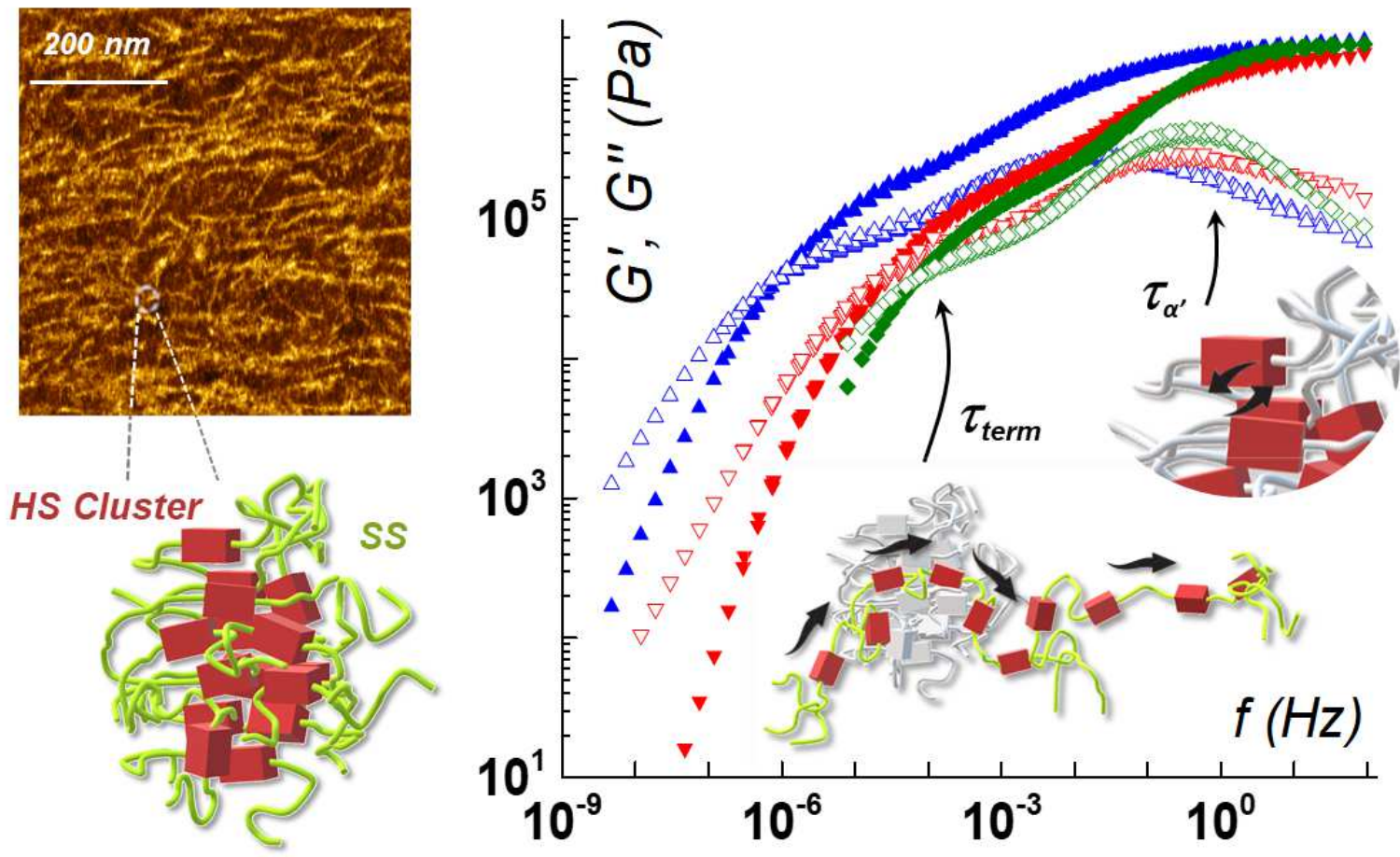